\title{
What drives relocation policies in the Maldives?
}

\author{
Geronimo Gussmann ${ }^{1,2}$ (D) Jochen Hinkel ${ }^{1,3}$ (DD
}

Received: 23 March 2020 / Accepted: 28 October 2020 /Published online: 20 November 2020

(C) The Author(s) 2020

\begin{abstract}
The predominant responses to rising sea levels are in situ adaptations. However, increasing rates of sea-level rise will render ex situ adaptations - in the form of relocationsinevitable in some low-lying coastal zones. Particularly small island states like the Maldives face this significant adaptation challenge. Here, government action is necessary to move vulnerable communities out of flood-prone areas. Yet, little empirical knowledge exists about the governance of relocations. While the literature often highlights risks and benefits of relocations, it remains unclear how governments organized relocations and what drove relocation policy. Therefore, we examined Maldivian relocation policies from 1968 to 2018 to explain government support of relocations. For this, we used a qualitative research design and extended the multiple streams approach with the theoretical lens of historical institutionalism. To gather data, we conducted semi-structured interviews $(n=$ 23 ) with relocation policy experts and locals affected by relocations. Interview data was complemented with a desk review of relevant laws, historical records, and policy documents. We find 29 completed and 25 failed cases of relocations in the 50-year period. Key drivers of relocation policies are focusing events, socioeconomic development, and institutionalized island autonomy. We find that relocations were predominantly initiated as means to facilitate economic development, not as a response to rising seas or coastal risk. With current rapid economic development and strengthened democratic institutions, relocations are not considered as a policy option anymore. We conclude that implementing relocations proactively will face significant barriers in the future, which highlights the urgency of successful in situ adaptations in the Maldives.
\end{abstract}

Keywords Sea-level rise $\cdot$ Coastal adaptation $\cdot$ Retreat $\cdot$ Multiple streams $\cdot$ New institutionalism

Geronimo Gussmann

geronimo.gussmann@globalclimateforum.org

Global Climate Forum, Neue Promenade 6, 10178 Berlin, Germany

2 Albrecht Daniel Thaer-Institute, Humboldt-Universität zu Berlin, Invalidenstraße 42, 10099 Berlin, Germany

3 Division of Resource Economics, Albrecht Daniel Thaer-Institute, Humboldt-Universität zu Berlin, Invalidenstraße 42, 10099 Berlin, Germany 


\section{Introduction}

Low-lying coastal zones and small island states face a significant adaptation challenge due to rising sea levels. Given the failure to substantially reduce global greenhouse gas emissions and the fact that sea levels will continue to rise for centuries due to the delayed response of the ocean to temperature increases (Oppenheimer et al. 2019), it is now consensus that coastal retreat will become inevitable for some communities in low-lying coastal zones (Siders et al. 2019).

The emerging literature on coastal retreat has mainly focused on community perspectives of coastal retreat. On the one hand, this includes describing the often-negative outcomes of relocation for communities. For example, Dannenberg et al. (2019) identified small communities relocated in the USA, Panama, Fiji, Papua New Guinea, Solomon Islands, and Vanuatu having suffered from disruption of livelihoods, impoverishment, loss of culture and identity, and psychological harm. Birk (2012) supports these findings who studied retreat in the Solomon Islands and argues that moving people into new locations could in fact create new vulnerabilities, e.g., due to limited access to resources and constraints to land ownership in the new settlement areas. On the other hand, this includes literature that has studied the motivations and preferences of communities with respect to retreat. For example, Jamero et al. (2017) studied responses to sea-level rise (SLR) in the Philippines and found that communities prefer in situ adaptations to a government-led relocation policy program, which fits into the overall picture that small island communities are often reluctant to retreat.

The public policy dimension of retreat, however, has hardly been studied. Generally, there is little empirical knowledge about what drove the design and content of retreat and relocation policies and which implications this has for adapting to sea-level rise. This constitutes a major limitation because government policies play a key role in facilitating retreat, by incentivizing individual migration or relocating people and assets out of vulnerable areas (Hauer et al. 2019). For example, reasons for negative outcomes of relocations on the affected communities are often found in a lack of planning, regulatory void, and lack of government accountability, highlighting the important role for policy (Dachary-Bernard et al. 2019; Mortreux et al. 2018; Siders 2019).

The few papers that have looked at governmental decision-making on retreat have focused on describing determinants that motivated government decisions at a snapshot in time, rather than policy processes and change in which these determinants are embedded. For example, Mortreux et al. (2018) studied what motivates or demotivates governments to act on retreat via relocation in West Bengal, India. They found that governmental inaction is driven by riskaverse politicians and a lack of accountability in a situation where no consistent relocation policy exists. The reluctance of politicians to implement relocation due to the high political risks has also generally been highlighted for retreat (Gibbs 2016). This literature, however, does not look at the formation and change of retreat policy. Determinants driving political decision-making, such as political risk and accountability are embedded and shaped by processes of policy and institutional change. A rich body of political science literature provides theories explaining the content and change of policies (Kingdon 1984; Sabatier 1987). However, to our knowledge, this has never been applied to retreat. Applying this literature to coastal retreat is particularly useful because it can provide insights to how future government policy may emerge.

Here, we address this gap in a case study of the Maldives. The main research question we address is, how did relocation policy in the Maldives evolve over time and what drove these 
policy changes? To answer this question, we first built a data-set of relocations from 1968 to 2018. In a second step, we explain relocation policy change over time with a qualitative comparative method that compares government support for relocations over seven policy phases, using the theoretical lenses of two well-established frameworks of political science: The multiple streams approach (MSA) and historical institutionalism (HI) (Kingdon 1984; Thelen and Steinmo 1992).

The Maldives is an ideal case to study relocation policy against the backdrop of SLR. With average land elevations ranging from 0.5 to $2.3 \mathrm{~m}$ above mean sea level, the Maldives are among the most vulnerable countries to SLR (Wadey et al. 2017). Adding to this, relocations have occurred in the Maldives for over 60 years (Maniku 1990). However, neither official documentation nor scientific literature exists that describes what drove relocations and policy. Understanding how and why relocation policies changed over time will contribute to closing these knowledge gaps and inform future policy.

The remainder of the paper is organized as follows. The second section illustrates the stateof-the-art of coastal adaptation in small islands with a focus on relocations as a response to coastal risks and the role of policy. The third section elaborates on the analytical framework used and data gathering methods applied. The fourth section presents the dataset of relocations and the evolution of government support for relocations over the analyzed period. This is followed by a discussion of our findings in the fifth section, before we conclude in the sixth section.

\section{Relocation as a response to coastal risks and sea-level rise}

Small island states like the Maldives are most vulnerable to SLR and its associated impacts. The main risks stem from flooding, saltwater intrusion, and shoreline changes threatening settlements. These risks challenge the future habitability of these low-lying atoll islands, and if no adaptation measures are taken, habitability thresholds could already be reached by midcentury (Storlazzi et al. 2018).

In situ adaptation, in the form of protection, accommodation, advance, either through hard engineering measures or through soft sediment-based and ecosystem-based measures can significantly extend island habitability. For example, urban islands can reduce risk through land raising which is already widespread (Bisaro et al. 2019), but this is unlikely to be a feasible solution for rural and poorer islands due to economic and financial constraints (Hinkel et al. 2018). In the latter places, ecosystem-based adaptation, e.g., in the form of planting mangroves or conserving corals can reduce coastal risks. However, coastal ecosystems are among those that currently experience very high rates of human destruction. For coral islands like the Maldives, the situation is specifically problematic, because most corals are expected to disappear due to ocean warming under only $2^{\circ} \mathrm{C}$ degrees of global warming (Oppenheimer et al. 2019).

This suggests that ex situ adaptation or retreat will be, sooner or later, a necessary response to coastal risks in small island regions. Retreat can happen gradually on an individual and voluntary basis with people migrating from one island to another (Oppenheimer et al. 2019). Retreat can, however, also be managed or planned by national governments via relocations and this is what this paper focuses upon by explaining different levels of national government support for relocation over time. 
In the adaptation pathways literature, managed retreat is often considered as an adaptation option of last resort, if in situ adaptations fail or SLR reaches a critical threshold (Barnett et al. 2014; Gibbs 2016; Ramm et al. 2018). Managed retreat may, however, also be proactively implemented in the face of rising sea levels, albeit this is often politically difficult because coastal communities are usually reluctant to move and decision-makers that support this response face high political risks. For example, Hanna et al. (2018) investigated barriers and enablers of managed retreat in New Zealand and find that a key barrier to implementing managed retreat is a lack of national policy guidance. Hence, government action on retreat has often followed extreme events or when habitability-thresholds have already been reached (Hino et al. 2017; Mortreux et al. 2018). Other than for migration (Hirsch 2015; Stojanov et al. 2017; Sovacool 2012), managed retreat or relocation has hardly been studied in the Maldives. As an exception, Kothari (2014) finds that climate change is used to justify unpopular relocation policies in the Maldives, but has not systematically compiled a dataset of neither relocations nor analyzed relocation policy change. Hence, we aim to explain the relocation policy change of the national Maldivian governments, not to be conflated with explaining relocation outcomes.

\section{Methods and materials}

\subsection{Putting the Maldives into context}

The Republic of Maldives is a small island state in the Indian Ocean and consists of ca. 1190 islands of which 188 were inhabited in 2014 (NBS 2017). The last census in 2014 counted a resident population of 437,500 people which is estimated to reach 557,400 in 2020 (NBS 2019). The capital Male is the economic and political center of the country, with roughly $40 \%$ of the people living in the Greater Malé area. High-end tourism is the key economic sector that facilitated rapid economic growth. In 2018, the gross domestic product was 10,330 USD per capita, being among the highest in South Asia (World Bank 2019).

The Maldives has had a turbulent political history in the last and ongoing century. The Maldives was a sultanate under British protectorate from 1887 until 1965 (cf. Hockly 1935). The population in the 1940s was around 90,000 people (World Bank 2019). In 1965, the Maldives gained independence from the UK and became a Republic in 1968 with Ibrahim Nasir as President. He was succeeded by Maumoon Abdul Gayoom in 1978 (Colton 1995). In 1987, following a swell event that flooded large parts of the country, Gayoom was the first Maldivian president to connect SLR and the vulnerability of small islands thereof on the international stage (see section 4.2.5). One outcome of this was the formation of the Alliance of Small Island States in 1990, which continues to play a major role in international climate negotiations. Gayoom remained president for 40 years until 2008, when he was challenged by Mohamed Nasheed calling for progressive reforms, e.g., multi-party elections and increasing democratic rights. Nasheed became the new president and continued Maldivian global climate leadership, e.g., by hosting a cabinet meeting underwater. He led the country until 2012 when he had to resign over political unrest due to his progressive reforms (Robinson 2016). He was succeeded by his vice president Mohamed Waheed until the next elections in 2013. The elections in 2013 were won by Abdulla Yameen whose term was accompanied with various commotions and can be characterized as an antipode to Nasheed's government. In the latest 
elections in 2018, Ibrahim Mohamed Solih became President following the footsteps of his party-colleague Nasheed.

Human mobility has a long tradition in the Maldives. People have moved from one island to another for various reasons in the past (Stojanov et al. 2017). For example, thirteen island communities individually moved to new islands, after heavy destruction following a storm in 1918 (Maniku 1990, p. 39). During these times, no relocation policies existed to our knowledge. Instead, island communities were mostly autonomous and governed themselves including decisions to move to a different island. This autonomous island governance was institutionalized over a long period of time but was increasingly challenged. Before gaining independence from the UK in 1965, the Maldivian relocation policy was influenced by British interests. For example, the community in S. Gan was moved to S. Feydhoo in 1956 to facilitate the expansion of a military airport in S. Gan by the British Royal Air Force. During this time, the regime was characterized by a strong hierarchy, patrimonial structures and relocations were conducted on an ad-hoc basis (see Colton 1995). This is also evident by the relocation of K. Viligili to K. Hulhule in 1961 to free up agricultural land near the capital Malé. We explain further relocation policy change starting in 1968, with the proclamation of the Maldivian republic (see section 4.2).

Currently, census data shows a strong net migration to Greater Malé, with individuals being motivated by factors such as employment opportunities, educational opportunities, and quality of health services rather than coastal risks or climate change (Speelman et al. 2016).

\subsection{Analytical framework}

Our analytical framework extends the MSA with the HI (Kingdon 1984; Thelen and Steinmo 1992). The MSA is a well-established framework for explaining agenda setting and policy change via the analysis of three streams: problem, policy, and politics (Zahariadis 2014). It was originally developed by Kingdon (1984), based on the garbage can model by Cohen et al. (1972), to explain United States federal policymaking. Since then, the MSA has been further developed and applied to various national, parliamentarian, and presidential cases in developed and developing countries (Atkins et al. 2012; Cairney and Jones 2016). Toward this end, multiple studies have made significant theoretical and empirical contributions by modifying the MSA to fit to their respective cases and analytical needs, for example by extending it with other policy change frameworks (Orach et al. 2017).

The MSA is based on the concepts of three independent streams, which are problem, policy, and politics streams that together with policy windows and policy entrepreneurs shape how the policy process unfolds.

The problem stream refers to the recognition and framing of problems relevant to the public and associated policymakers that are in search of corresponding solutions. Changes in the problem stream are often induced by focusing events such as disasters or accidents, feedback from stakeholders, or relevant indicators such as cost increases (Zahariadis 2014).

The policy stream refers to the solutions proposed by experts and analysts who examine the problems (Béland and Howlett 2016). Solutions are selected based on technical feasibility and value acceptability (Zahariadis 2014). Those solutions considered adequate may change over time. For example, competitive pressure between experts and analysts can induce change in the policy stream, mostly following a change in interests in the policy community (Mahoney 2000). Moreover, the search for alternative solutions is often influenced by processes of policy learning for example, via policy imitation. Here, the argument is that policy communities 
would imitate successful policy solutions or instruments from similar domains or organizations due to uncertainty. Lastly, interest groups can feed solutions to the policy stream via lobbying (Spohr 2016).

The politics stream refers to factors that influence the policymakers including national mood, power balances, and changes in values or beliefs. Change in the politics stream can be induced by changes in these factors or legislative turnover of policymakers (Zahariadis 2014).

Kingdon (1984) argues that when these more or less independent streams are coupled during a policy window, policy change is likely to occur. Such a coupling of streams means that a problem is recognized as a policy issue within the problem stream to which a policy solution exists within the policy community (policy stream) while the political situation allows for its implementation (politics stream). Policy windows can be opened by external focusing events such as regime changes, natural disasters, or accidents (Béland and Howlett 2016). Another key role in coupling the streams have policy entrepreneurs, which are best understood as "well-informed and well-connected insiders who provide the knowledge and tenacity to help couple the "streams"' (Cairney and Jones 2016, p. 41). Policy entrepreneurs can be politicians, lobbyists, or even head of governments.

We modify and extend the MSA in two ways. First, we focus on a subset of policy entrepreneurs: national leaders who are in a more legitimate and powerful position to couple and steer the streams also referred to as political entrepreneurs cf. Herweg et al. (2015). This focus allows us to account for the traditionally strong national leadership in the Maldives (see Colton 1995). Second, we extend the MSA with concepts from HI to account for the longitudinal character of our study and multiple policy cycles. This allows us to take into account how long-term societal changes, outside of the formal administrative processes, influence the evolution of policy (Spohr 2016). Especially, in countries with a high extent of non-formalized governance, the integration of the institutional context is key to provide a full picture of policy drivers (Helmke and Levitsky 2006).

$\mathrm{HI}$ is one of three main variants of New Institutionalism. HI aims to explain how the institutional context shapes behavior and outcomes. Here, institutions - the norms, rules, and conventions shaping behavior - are understood as "products of historically-situated interactions, conflicts and negotiations" among societal actors (Thelen and Steinmo 1992). These interactions among societal actors can happen in various formal and informal arenas of decision-making, for example, between experts in government that formulate a policy or between local fishers allocating fishing grounds among themselves.

We use two concepts from HI for our analytical framework. The first concept is institutional stability, which describes that the institutional context tends to be stable over long periods of time. This institutional stability can be explained by institutional inertia such as costs or uncertainty which results in path dependency, for example via the lock-in of technological systems (Munck af Rosenschöld et al. 2014). The second concept we use from $\mathrm{HI}$ is that the institutional context constrains the range of policy choices available to policymakers (Campbell 1998). This is an important extension to the MSA which only accounts for the value acceptability of the policy community for selecting potential policy solutions in the policy stream (Zahariadis 2014), but not the underlying normative structures of society. However, a policy that competes with the existing norms, rules, and conventions of social behavior is likely to be ineffective or rejected due to institutional constraint. For example, if setback zones aimed at reducing coastal risks interfere with local conventions to build directly at the coast, compliance to the setback policy will be 
low (Lincke et al. 2020). Nevertheless, this logic goes both ways: New policies may also change informal social norms or rules.

The relationship between policies and institutions is part of an ongoing discussion in the institutionalist literature. Here, we understand policies as "positions taken and communicated by governments - 'avowals of intent' that recognize a problem and in general terms state what will be done about it" (Dovers and Hezri 2010, p. 222). Policies can be thought of as a subcategory of institutions.

\subsection{Data gathering and analysis}

For compiling the dataset of relocations, we used the Statistical Yearbook of the Maldives 2017 (NBS 2017), academic literature (Kothari 2014; Luetz 2017), and secondary literature (Ibrahim 2016; Maniku 1990; Nafees 2005; Shaig 2008). The documents for our review were identified via internet searches, archival searches in the National Library of the Maldives, Malé, and complemented with documents provided by interview respondents (see Supplementary Material 4). We then compiled reported successful and failed relocation cases as follows.

We considered national government-led relocations only, starting in 1968 when the Maldives became a Republic, and ignored autonomous mobility of communities. Where possible, we documented the destination island, the date of relocation, the reported reason, and the number of people relocated. For relocations that occurred after the tsunami in 2004, we used available census data from the previously inhabited islands in 2000 or 2006, depending on the date of relocation, as an approximation of relocated people (NBS 2017). For earlier cases where only the number of relocated households was reported, we assumed the earliest reported average household size of six persons from 2002 (Ministry of Finance and Treasury 2012). For cases, where we found conflicting information, we gave preference to officially reported information-from the Statistical Yearbook-for example in the case of reasons for relocation (see Table 1).

We documented both, successful and failed relocations. For successful relocations, only complete relocations were considered. For example, relocations where part of the community remained on an island were not considered as successful. For failed relocations, we included cases of planned but not-executed relocations as well as cases in which communities returned to their home islands after being relocated earlier (see Supplementary Material 5). We again aimed to document home and destination island, the populations at the time of initiation, the reported reason for the relocation and the reason for failure.

The completeness of the dataset was double checked by a senior policy expert who was previously involved in the process of relocations and has over 20 years of working experience in various Maldivian ministries overseeing relocation.

To explain varying government support for relocations, we conducted semi-structured interviews $(n=23)$ complemented with a desk review of further strategy, plan, and other policy documents, e.g., speeches (see Supplementary Material 4). The documents for our review were again identified via internet searches, archival searches, and complemented with documents provided by interview respondents. We scanned and analyzed the documents for positions taken and communicated by the national Maldivian governments that recognized a problem and stated relocations as a possible solution. Interviews were conducted in the Maldives in February and March 2019 and followed a semi-structured interview guide (see 
Table 1 Relocations from 1968 to 2018

\begin{tabular}{|c|c|c|c|c|c|}
\hline $\begin{array}{l}\text { Date of } \\
\text { relocation }\end{array}$ & Home island & Destination island & $\begin{array}{l}\text { Reported reason for } \\
\text { initiation }\end{array}$ & $\begin{array}{l}\text { Policy } \\
\text { phase }\end{array}$ & $\begin{array}{l}\text { Population } \\
\text { moved }\end{array}$ \\
\hline 1968 & K. Giraavaru & K. Hulhule & Law 6/68** & 1 & Unknown \\
\hline 1968 & R. Ufulandhoo & R. Alifushi & Law $6 / 68 * *$ & 1 & 93 \\
\hline 1968 & F. Himithi & F. Nilandhoo & Law $6 / 68 * *$ & 1 & 48 \\
\hline 1968 & B. U'doodhoo & B. Eydhafushi & Law $6 / 68 * *$ & 1 & 87 \\
\hline 1968 & B. Funadhoo & B. Eydhafushi & Law $6 / 68 * *$ & 1 & 138 \\
\hline 1969 & B. Maahdoo & B. Eydhafushi & Law $6 / 68 * *$ & 1 & 132 \\
\hline 1970 & AA. Kuramathi & AA. Rasdhoo & Law 6/68** & 1 & 124 \\
\hline 1971 & Sh. Bomasdhoo & Sh. Farukolhu & Law $6 / 68 * *$ & 1 & 177 \\
\hline 1992 & Sh. Tholhendhoo & Sh. Kendhikulhudhoo & opulation consolidation $* *$ & 4 & 171 \\
\hline 1995 & R. Ugulu & R. Hulhudhofaaru & Population consolidation $* *$ & 4 & 521 \\
\hline 1995 & R. Gaaudoodhoo & R. Hulhudhofaaru & Population consolidation $* *$ & 4 & 461 \\
\hline 1997 & Sh. Maakandoodhoo & Sh. Milandhoo & Population consolidation* & 4 & 1606 \\
\hline 1999 & Hdh. Hondaidhoo & Hdh. Nolhivaranfaru & Population consolidation* & 5 & 169 \\
\hline 2006 & Hdh. Gemendhoo & Hdh. Kudahuvadhoo & Tsunami* & 5 & 322 \\
\hline 2006 & M. Madifushi & Adh. Maamigili & Tsunami** & 5 & 122 \\
\hline 2006 & Adh. Rinbudhoo & K. Thulusdhoo & Tsunami** & 5 & 420 \\
\hline 2006 & Sh. Noomaraa & Sh. Funadhoo & Population consolidation* & 5 & 348 \\
\hline 2007 & HA. Berinmadhoo & HA. Hoarafushi & Population consolidation* & 5 & 174 \\
\hline 2007 & Sh. Firunbaidhoo & Sh. Funadhoo & Tsunami & 5 & 413 \\
\hline 2008 & HA. Hathifushi & HA. Hanimaadhoo & Population consolidation* & 6 & 101 \\
\hline 2009 & R. Kandholhudhu & R. Dhuvaafaru & Tsunami* & 6 & 2717 \\
\hline 2009 & Hdh. Faridhoo & Hdh. Nolhivaranfaru & Population consolidation* & 6 & 87 \\
\hline 2009 & Hdh. Kunburudhoo & Hdh. Nolhivaranfaru & Population consolidation* & 6 & 325 \\
\hline 2009 & Hdh. Maavaidhoo & Hdh. Nolhivaranfaru & Population consolidation* & 6 & 190 \\
\hline 2010 & GA. Dhiyadhoo & GA. Gemanafushi & Tsunami** & 6 & 139 \\
\hline 2010 & L. Kalhaidhoo & L. Gan & Tsunami** & 6 & 434 \\
\hline 2012 & Hdh. Vaanee & Hdh. Kudahuvadhoo & $\begin{array}{l}\text { Tsunami/population } \\
\text { consolidation* }\end{array}$ & 6 & 211 \\
\hline 2014 & Lh. Maafilaafushi & HA. Hanimaadhoo & Population consolidation* & 6 & 130 \\
\hline 2016 & L. Gadhoo & L. Fonadhoo & Population consolidation $* *$ & 6 & 480 \\
\hline
\end{tabular}

Note: Officially reported reasons are marked with “*”, where official reasons were not available we used gray literature and interview data marked with “**”. In cases where multiple reasons were given, we report the official reported reason. See Supplementary Material 3 for a list of administrative atoll abbreviations

Supplementary Material 2). Interviews were conducted in English and mostly recorded after obtaining informed consent and guaranteeing confidentiality. In some cases, however, respondents opted against being recorded or recording was stopped and later continued for parts of the interview, if respondents were not confident to answer a question on record.

We first conducted two interviews with senior officials from the Maldivian government to obtain an overview of relevant current and former organizations, processes, events, and individuals. Based on this and the aforementioned documents, we developed a list of relevant organizations and actors that were involved in the process of relocations. We then conducted 12 additional interviews with respondents from the identified (former) government organizations, non-governmental organizations (NGOs), and civil society. We paid close attention to include diverse perspectives from civil society and NGOs. Therefore, we conducted nine interviews with community leaders and individuals involved in relocation processes in Laamu atoll. We used the data gained through these local interviews as background information. This data allowed us to triangulate and validate data retrieved at the national level with data of lived 
experiences. We relied on the provision of contacts by the respondents due to the close expert networks in the Maldives and the difficulty to access former government officials that were not affiliated with the government anymore.

We used MAXQDA2018 Pro to transcribe and code the interviews and documents for the policy analysis. We applied deductive coding (Flick 2014), using the concepts from our analytical framework as introduced above.

To explain relocation-policy change and identify its drivers, we started with a periodization of our analytical period. Periodization is key for historical analysis and allows for a simplification of a chronology by dividing it into analytical parts. These phases are usually bound by important events, changes, or turning points (Lieberman 2001). Here, we use changes in government support for relocations to divide our analytical period into different phases.

We then examined our independent variables (the multiple streams and the institutional context) for each phase to explain variation in our dependent variable (government support for relocations) and compared them across phases. Lastly, in order to align the quantitative data on observed relocations with the policy evolution, we inductively developed a scale to categorize the policy output of each phase. This allows us to show the evolution of policy change along our analytical period.

\section{Results}

\subsection{Relocations from 1968 to 2018}

We identified 29 completed relocations between 1968 and 2018. Additionally, we found 25 cases of initiated but not executed relocations or cases where communities returned to their home islands after being relocated (see Supplementary Material 5). A conservative approximation of the relocated population is 10,100 . Reported reasons for the relocations, from official and unofficial documents, range from military use, unclear, tsunami impacts to a Population Consolidation Program (PCP).

We find two major relocation periods. The first period started in 1968 after the proclamation of the second Maldivian republic, 20 island communities were relocated. For twelve of these, the population returned to their island in 1975 (see Supplementary Material 5). The second period started after the tsunami of 2004. Following the vast destruction of this extreme event, 17 relocations were officially initiated, of which 14 were carried out (see Table 1 and Supplementary Material 5).

The largest relocation in terms of resettled population was R. Kandholhudhu to R. Dhuvaafaru with 2717 people in 2009 . Here, the previously uninhabited R. Dhuvaafaru was explicitly developed to host the tsunami-displaced community. Plans to develop R. Dhuvaafaru were initiated after the tsunami and finished in 2009 (see Supplementary Material 1).

\subsection{Phases and drivers of relocation policy change}

We identified seven relocation policy phases between 1968 and 2018, which we characterized in terms of their degree of formalization and the extent to which the government promoted or demoted relocations. Together this gave us the following five types of relocation policies on an ordinal scale from formal promotion of relocations to demotion of relocations: (i) government promotes relocations through formal laws or regulations; (ii) government promotes relocations 
officially but without formalization into laws or regulations; (iii) government promotes relocations unofficially via informal channels and individuals; (iv) no clear promotion or demotion, rather ad hoc government decision, and (v) government demotes relocations (see Fig. 1). In the following, we analyze the multiple streams and institutional context for each phase, explain the relocation-policy changes and motivate the classification of each phase into one of these five categories.

\subsubsection{8-1975 first major relocation episode}

After gaining independence in 1965, a conflict for power between monarchists and republicans arose, which was decided in favor of the republicans. Hence, the Maldives became a republic in 1968. As described above (see section 3.1), before 1968, no relocation policies existed but the Maldivian government had used relocations on an ad hoc basis, e.g., to free-up agricultural land near the capital or for the construction of a British military base. However, the regime change served as a focusing event that influenced the multiple streams and opened a policy window. As a result, the Maldives saw significant policy change and their first major relocation episode. Policy change was triggered in the problem stream: The new government faced internal power struggles against dissidents in favor of the old monarchy and had difficulties to establish governance across the over 200 inhabited islands. Hence, the geographical dispersion of the population was soon recognized as a problem in Malé.

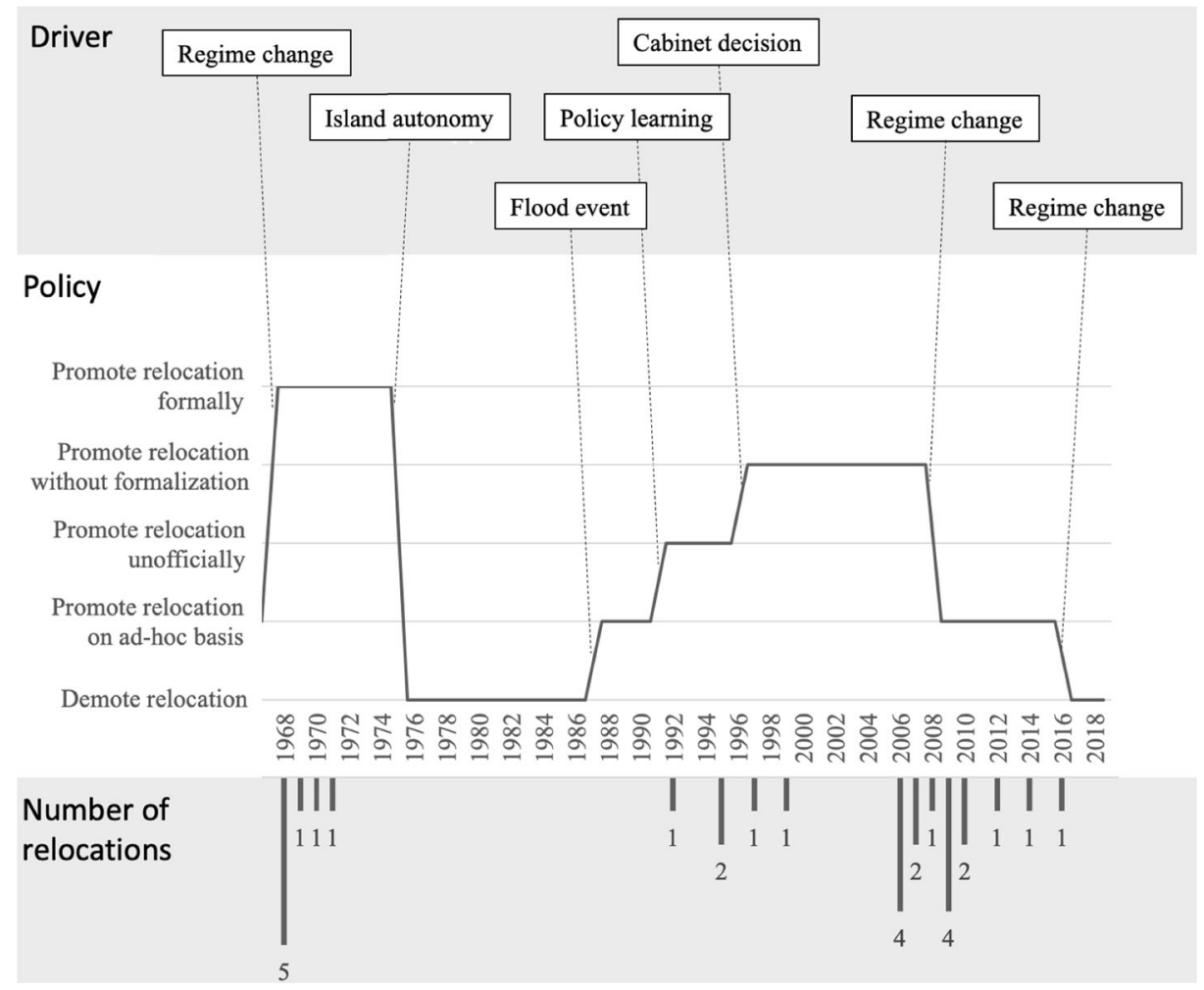

Fig. 1 Drivers, policy, and number of relocations in the Maldives from 1968 to 2018 
The previous experience and learning processes from the relocations before our analytical period provided relocations as a solution to this problem in the policy stream. Additionally, the ability to influence the politics stream due to the strong hierarchy allowed for drastic policy change. As a result, the new government passed the Law 6/68, which until today remains the only formal promotion of a Maldivian government to relocate.

Law $6 / 68$ set out a major relocation program. It required islands with less than 50 adult men to relocate to denser populated islands. The reason put forward was the inability of small communities to perform Muslim Friday Prayers appropriately. "The notion of not enough people for Friday prayers - that probably was an excuse by the government" reported a policy expert from an NGO whose home island received relocatees in 1968. In total, 22 island communities were relocated.

\subsubsection{5-1987 no relocations and rapid economic development}

Law 6/68 stood in contrast with the previously long-established institution of island autonomy. It was therefore in danger to be inefficient or even rejected. In fact, the institutional constraint was later shown when the law was repealed in 1975 due to continuing power struggles between monarchists and republicans. In the aftermath, twelve of the 20 relocated communities returned to their home islands (see Supplementary Material 5).

The repeal of law 6/68, removed relocations from the agenda for the next 12 years. Island autonomy remained a stable institution. However, the Maldives went through a phase of rapid socioeconomic development during this period and beyond. In 1968, the Maldivian population was around 100,000 and mostly relied on agriculture and fisheries for their livelihoods (World Bank 2019). This picture then changed in the 1970s with the introduction of high-end tourism and the first resorts. In 1987, the Maldivian population had doubled and was around 200,000. Economic development became the major rational of the Maldivian government that was headed by President Maumoon Abdul Gayoom since 1978. During this policy phase, the government did not promote relocations.

\subsubsection{7-1992 focusing event and policy learning}

A focusing event in 1987 induced change in the problem stream which initiated an about turn of the government's relocation policy. On 10 April 1987, a swell wave event caused severe damages throughout the country and accounted for the highest sea-level records at the time (cf. Wadey et al. 2017).

After the swell wave event, the high coastal vulnerability of the Maldives moved up in the problem stream and was linked to the emerging debate of global warming. During a speech at the UN, right after the swell wave event, President Gayoom stressed this vulnerability of the Maldives to future SLR for the first time: "As for [...] the Maldives, a mean sea-level rise of 2 metres would suffice virtually to submerge the entire country of 1190 small islands, most of which barely rise over 2 metres above mean sea level. That would be the death of a nation." (Gayoom 1987). This statement stands representative for the increased recognition of the SLR risk in the problem stream. It was recognized that SLR will require solutions in the future and that the geographical dispersion of the population across many inhabited islands and their low land elevation will make this a complicated endeavor. A respondent from a former government put it this way: "The thinking we had was, we cannot continue with protection. With the budget coming in it was impossible." 
The solution for this problem, however, had not yet entered the policy stream at this point. Global warming and SLR were new phenomena and solutions first had to be established. Here, changes in the policy stream again occurred via policy learning, but this time triggered through the international level. Soon after the swell wave event, the First Assessment Report of the Intergovernmental Panel on Climate Change was published in May 1989 (IPCC and Houghton 1990). Looking for solutions, the Maldivian policy community acknowledged the three general responses to SLR put forward in this report: protect, accommodate, and retreat.

The change in the policy stream then occurred later in 1989. Building on the momentum of the IPCC report, the Maldives initiated the first Small States Conference on Sea-Level Rise and Global Warming in November to lobby for increased international attention on the matter. The outcome was the initiation of the Alliance of Small Island States and the Malé Declaration, which called for the review of existing development programs in small island states in face of relevant responses to SLR (Malé Declaration 1989). Key constraints for successful economic development were the geographically dispersed population vulnerable to SLR and the small government budget unable to invest sufficiently in the peripheral atolls. Hence, relocations as a solution to these constraints moved up in the policy stream and were considered by the policy community.

Simultaneously, the politics stream changed as well. The regime under President Gayoom became increasingly established. This allowed the government to govern freely, without major resistances or checks and balances. Based on the changes in the politics stream and the other streams as described above, policy change occurred. Given the conditions in the politics stream, this change was initiated at the top level of the national government. Now, the government-supported relocating scarcely populated islands to facilitate economic development.

\subsubsection{2-1997 path toward the PCP}

Policy change from ad hoc relocations toward unofficial promotion to relocate was then manifested in 1992. Upon visitations of President Gayoom in HA. Berinmadhoo and HA. Hathifushi, respondents claimed that plans of relocations spread in the two islands. In the case of Berinmadhoo, concrete steps in the form of building bans were issued. However, following complaints of the local communities, these plans were discarded at this time (both communities were relocated after the tsunami (see Table 1). Contrastingly, Sh. Tholendhoo was relocated in 1992. The reason remains unclear: "At the time we didn't have a policy for relocation", reported a respondent from the government, highlighting the informal and unofficial character of these relocations efforts.

The relocation policies of the government became more official after 1993 and moved up in the policy stream. Based on the resistance of local communities to relocate, the government introduced compensations. Relocated households were granted compensation for their primary homes, palm trees, and initial construction of infrastructure in the new islands, e.g., roads in front of the new house. As a result, R. Ungulhu and R. Gaaundoodhoo were relocated in 1995. This was well received in the policy community and resulted in a cabinet decision in 1996 stating the importance to move communities of an underdeveloped and scarcely populated island to a bigger, more developed island. At this time, 75 (37\%) of the 201 inhabited islands had less than 500 inhabitants (NBS 2017). 


\subsubsection{7-2008 unpopular population consolidation and the Indian Ocean tsunami}

Building on the cabinet decision, President Gayoom announced the PCP during a keynote at a workshop for atoll chiefs in 1997. The PCP was supposed to increase economies of scale, improve living standards and economic opportunities. It addressed the problem to economically develop a geographically dispersed country under budget constraints. In fact, respondents highlighted the difficulty to provide state and municipal services across the 201 inhabited islands with the low government budget. However, the PCP was met with reluctance among the population and never translated into a formal policy or law. This again indicates institutional constraint. Nevertheless, the government continued to plan and officially promote relocations.

n 2004, the Indian Ocean tsunami devastated many coastal communities in the region. This event opened a window of opportunity for the Maldivian government to implement the PCP. Albeit no policy change occurred - the government still followed its policy from 1997-the disaster allowed for the implementation of the already planned relocations. The vast destruction, fatalities, and internal displacement brought about by the tsunami facilitated this and lowered the reluctance of the communities: "A few days after the tsunami, they [the government] decided to relocate Mundoo and Kalaidoo. They visited the island and decided Mundoo and Kalhaidoo should be brought to Gan. They decided and announced it from government media" (respondent, local leader from Laamu atoll). Relocations were in some cases framed as coastal risk-reducing and some destination islands were called safer islands, appealing to the insecurity of the populations after the tsunami (see Riyaz and Park 2010). In total, the government had plans to relocate 17 island communities, of which 14 were finally relocated. However, despite the framing of reducing coastal risks, the paradigm for relocations from the government perspective remained the reduction of government expenses and the increase of economies of scale as formulated in the PCP.

\subsubsection{8-2018 formalization of relocation laws and individual migration}

The Maldives underwent significant institutional and policy change prior to and in the aftermath of the tsunami. After being increasingly challenged by progressive forces, the long-reigning government allowed gradual political reforms and was subsequently voted out of office in the first multi-party elections in 2008. This had a major influence on multiple streams.

The new government inherited the legacy of relocations that were already initiated after the tsunami. However, with the goal to increase transparency and to decentralize the country, many of the not-far-advanced relocations were canceled and individual migration was increasingly promoted (see Supplementary Material 5).

The decentralization program has been planned with the vision that people will migrate by choice to regions where more prosperity and better services are available. The Government has put in place a national transportation system as a means to overcome the transportation barrier throughout the nation. Thus, instead of measures for resettlement in other localities through incentive benefits, measures assisting voluntary migration will, in time, facilitate the achievement of the policy of population consolidation. (Ministry of Environment and Energy 2011, p. 30) 
This policy change can be explained with the significant changes in the politics stream that went along with the strengthening of democratic institutions. Top-down relocation decisions did not fit the values and beliefs of the population and new policymakers anymore.

The policy community, however, did not abandon relocations as a solution to the vast geographical dispersion of the population which still posited a problem for the government in terms of expenditure. As a result, formal rules for relocations were brought forward with the implementation of the Decentralization Act in 2010:

$[\mathrm{T}]$ he government has the power to relocate the inhabitants of an island or islands from inhabited islands of administrative divisions of the Maldives when this Act is promulgated. However, people from an inhabited island can be relocated to another island in this manner only with the consent of the majority of the island's population. ( $\$ 13, \mathrm{Nr}$. 135, Ministry of Home Affairs 2010).

Despite this first formal law addressing relocations since 1968, the government policy solely promoted relocations on an ad hoc basis. Relocations became incompatible with the goals of the government and the institutional context. Hence, no relocations were initiated by this government. It is worth mentioning though that the influence of the tsunami had a lasting impact on the framing of relocations as it was used as a reported reason for relocation until 2012 (see Table 1).

Adding to these developments were changes in the problem stream. In 2010, the introduction of value added taxes created a significant tax base allowing the government to increase spending for smaller islands. Hence, harbor developments and connectivity increased. This moved geographical dispersion down in the problem stream. Simultaneously, the Maldives graduated from the LDC status in 2011 and became a lower-middle-income country with a total population of 365,700 . Thus, the motivation of the PCP for relocations diminished. At the time of the last relocation in 2016, the Maldives was one of the wealthiest countries in South Asia in terms of GDP per capita with a population of 475,500 (World Bank 2019).

After a coup and an intermediary government, finally, a third government gained control in 2013. Turning away from the goal of decentralizing the country, the Yameen-government instead promoted individual migration toward the capital and the newly reclaimed suburban island Hulhumalé. Hence, only two relocations were conducted since 2013. Reasons for these remain unclear, i.e., the government promoted relocations on an ad hoc basis.

\subsubsection{8 no more relocations}

The last policy change occurred in 2018 after the election of a new government. This government refocuses on strengthening democratic institutions and regional development, following the path of the government in 2008. In fact, relocations moved down in both, the problem and policy stream. With respect to the problem stream, the rapidly increasing socioeconomic development and government revenue allowed for significant investments in most inhabited islands, e.g., most islands now have a harbor and access to basic medical services. This is highlighted by a respondent from a Maldivian NGO:

Now, every island has a harbor for 30-40 MVR million, sewerage, running water and there is a promise that every atoll has an airport. So, they will not move. If some of the communities would have been asked today to move, they would have refused. You can only have handcuffed them for it. 
With respect to the policy stream, the strengthening of democratic institutions contributed to abandoning relocations as a policy option. Hence, the government currently demotes relocations.

\section{Discussion}

Focusing events, socioeconomic development, and the institutional constraint are key drivers of relocation policy in the Maldives. In particular, the regime change in 1968, the flood event in 1987, and the regime change in 2008 had major influence on policy. During these events, the institutional constraints on policy were altered and either allowed or limited the implementation of relocations. Moreover, the main paradigm for relocations, facilitating economic development, disappeared more and more through the rapid socioeconomic development of the Maldives. Increasing welfare per capita, tax revenues, and built infrastructure on the islands let the need and legitimacy of relocations plummet.

From a methodological perspective, this study confirmed the value of using and extending the MSA with the HI and to focus on national leaders as political entrepreneurs to explain policy change in the Maldives (Spohr 2016; Zahariadis 2015). Our findings highlight the interplay between institutions and policies and the ability of national leaders to drive the policy process. On the one hand, we show the constraining effect informal institutions have on the range of policy options available to policymakers. The deeply rooted societal norm of island autonomy has prevailed over the course of the analysis and significantly constrained the implementation and formalization of relocation policies. On the other hand, during phases of reduced institutional constraint, e.g., after a focusing event, the top-down implementation of relocation policies was possible for powerful policymakers.

Our findings complement previous studies that aimed to explain the relocation decisions of governments through properties of the political system. We add to this with a focus on policy processes. For example, Mortreux et al. (2018) focus on snapshots in time to explain relocation outcomes in situations for which no consistent policy existed and perceived habitability thresholds had been reached. In contrast, our longitudinal approach identified drivers and examined how the national government's policy evolved over time in a situation for which relocations did not exclusively address environmental hazards.

These findings are particularly insightful for relocation practitioners as they shed light on the complex institutional processes and drivers that shape relocation policy. For example, international disaster relief and other climate funding agencies should be cautious in facilitating relocations of communities, especially in the aftermath of disasters like the tsunami in the Maldives. Our findings show that governments can promote relocations unofficially via informal channels and individuals and use extreme events as windows of opportunities to implement unpopular and informal relocation policies (Kothari 2014).

Our findings also add to existing knowledge on relocation policies in the Maldives (Kothari 2014) and confirm the importance of disentangling development narratives from SLR-induced relocations (Arnall 2019). The role of coastal risks and sea-level rise in the evolution of relocation policies in the Maldives is limited. Although the reduction of coastal risks in the tsunami aftermath was used as a framing for some relocations, the paradigm of economic development prevailed. It is striking how little SLR considerations have entered and affected the implementation of relocation policies, given all the leadership that the Maldives have had on the 
issue in recent decades. It seems that there was - and may still is - a disconnect between rhetoric on the global stage and domestic policies. This is an important insight, especially for global climate finance and adaptation practitioners that need to ensure that efforts are actually directed toward reducing climate vulnerability and not solely feed into economic development plans.

The current government policy raises the question of whether the proactive implementation of relocations is likely to be a widespread adaptation option under future SLR? Judging from the policy evolution, this is unlikely to be the case. The shift away from promoting relocations in 2008 has created a path dependency. This can be seen in the large number of non-executed relocations after 2008 (policy phase 6; see Supplementary Material 5) and the current government's position toward relocations. Referring to the widespread practice of moving trees from residential or uninhabited islands to new tourist resorts in the Maldives, a cabinet member put it this way: "people are not trees, you cannot simply move them". Instead of relocating communities, the current government policy aims to foster regional development. This development will continue to increase built infrastructure and hence increase the reluctance of communities to leave their islands. However, it is unclear if a policy of in situ adaptations can be applied to all 188 inhabited islands, not the least due to economic reasons.

Adaptation practitioners should therefore increasingly work toward the goal of developing comprehensive national adaptation plans in the Maldives that account for the complex institutional and political drivers of relocations that we point out. This also points toward the area of tension between the policy goal of moving people out of harm's way and the ties of vulnerable communities to their place (Hanna et al. 2020). Including these tensions into adaptation decision-making is pivotal for successful adaptation planning.

It is, however, also questionable if the current in situ adaptation policy will reduce coastal risks sufficiently, in particular for islands with low population densities. As of 2014, still 51 inhabited islands (27\%) had less than 500 inhabitants, and protecting such islands with low population density is very cost-ineffective and this is likely to exceed available government funds for coastal protection (Gussmann and Hinkel 2021). The lack of effective public adaptation policy for both relocation and protection, together with the increasing frequency and intensity of extreme events under SLR, could potentially create so-called trapped populations, which are populations that are neither sufficiently protected nor able to migrate (Hauer et al. 2019; Mortreux et al. 2018). This suggests that future relocations or migration will more likely take place reactively. In the case that an extreme event, exaggerated by SLR, would cause widespread destruction and displacement, relocating affected communities to higher-elevated islands would be a meaningful adaptation measure.

In this context, it is important to note that our analysis of national government-led relocations ignores larger patterns of individual migration within the Maldives. We do not want to imply that without government-sponsored relocation, people would stay in place. In fact, autonomous migration is another form of managed retreat and could be occurring at larger scales when there is no government action. Recent government reports about migration patterns in the Maldives point toward this direction with high internal mobility toward the urban center of Malé (NBS 2018).

This study faces some limitations. Although we compiled our dataset with high scrutiny and double checked with experts, it is possible that our dataset is still incomplete. Especially, relying on reported reasons for relocations bears potential for skewing our data. Moreover, identifying failed relocations proved to be difficult because no official documentation exists and planning and initiation were often informal. Hence, to avoid biased information, we paid close attention to verify our data with other existing sources and checked for alternative explanations. Additionally, the scope of our study did not allow us to open up the black box 
of policy implementation, i.e., we did not explain relocation outcomes. Although we document the number of relocations, it remains unclear why some relocations were implemented and others failed. For this, more in-depth research is clearly needed. Lastly, it is an identified research gap in the multiple-streams literature that the MSA needs to be modified according to the respective regime context, because the literature expects differences between e.g. the policy processes of one-party and multi-party systems (Herweg et al. 2018). However, contributing to this theory development, apart from the MSA-modifications described above, was out of the scope for this study.

\section{Conclusion}

This study documented relocation cases and explained the evolution of relocation policies in the Maldives from 1968 to 2018. We found seven phases of relocation policy change and two major relocation episodes within. Policy change was driven by focusing events such as regime change in 2008, institutional constraints such as island autonomy, and socioeconomic development such as increasing welfare, tax incomes, and built infrastructure on the islands.

We used a qualitative multi-method research design for this study. The extension of the MSA with concepts from the HI allowed us to take account of the broader historical institutional context. This context helped in explaining policy changes during our analytical period. Especially, the role of institutional constraints on reducing the range of policy options available to decision makers and hindering the extent of policy formalization was key to explain policy change and output.

The increasing economic development on the islands paired with the reluctance of policymakers and communities to relocate, demonstrates the increasing difficulty to proactively implement relocations in the future. However, against the background of increasing intensity and frequency of extreme flood events due to SLR, inaction to get vulnerable communities out of flood-prone areas could lead to detrimental consequences. Furthermore, our findings challenge the reliance of relocations as an adaptation option of last resort in small islands and highlight the urgency of successful in situ adaptations. Yet, it remains unclear to what extent in situ adaptations will be feasible and successful for small communities in the long run, i.e., beyond 2100 .

Further research should address the looming questions of policy implementation: Why did some relocations fail, how were islands selected for relocations, and how were a majority of the relocations organized in the absence of formal rules? For this, process tracing of specific relocation cases in the Maldives appears most promising to gain insights on why relocations succeeded or failed. The knowledge gained through such studies would further enhance our understanding of the complex social and political dynamics underpinning the relocation-sealevel-rise nexus.

Supplementary Information The online version contains supplementary material available at https://oi. org/10.1007/s10584-020-02919-8.

Acknowledgments We thank all Maldivian respondents for their time and efforts. We also thank two anonymous reviewers for helping us to improve our manuscript. 
Author contributions GG: Conceptualization, methodology, validation, formal analysis, investigation, data curation, writing — original draft, visualization.

JH: Validation, resources, writing - review and editing, supervision, project administration, funding acquisition.

Funding Open Access funding enabled and organized by Projekt DEAL. GG and JH have received funding from the project INSeaPTION, which is part of ERA4CS, an ERA-NET initiated by JPI Climate, and funded by FORMAS (SE), BMBF (DE), BMWFW (AT), IFD (DK), MINECO (ES), ANR (FR) with co-funding by the European Union (Grant 690462).

\title{
Data availability N/A
}

\section{Compliance with ethical standards}

Conflict of interest The authors declare that they have no conflict of interest.

\author{
Code availability $\mathrm{N} / \mathrm{A}$
}

Open Access This article is licensed under a Creative Commons Attribution 4.0 International License, which permits use, sharing, adaptation, distribution and reproduction in any medium or format, as long as you give appropriate credit to the original author(s) and the source, provide a link to the Creative Commons licence, and indicate if changes were made. The images or other third party material in this article are included in the article's Creative Commons licence, unless indicated otherwise in a credit line to the material. If material is not included in the article's Creative Commons licence and your intended use is not permitted by statutory regulation or exceeds the permitted use, you will need to obtain permission directly from the copyright holder. To view a copy of this licence, visit http://creativecommons.org/licenses/by/4.0/.

\section{References}

Arnall A (2019) Resettlement as climate change adaptation: what can be learned from state-led relocation in rural Africa and Asia? Clim Dev 11:253-263. https://doi.org/10.1080/17565529.2018.1442799

Atkins S, Lewin S, Ringsberg KC, Thorson A (2012) Towards an empowerment approach in tuberculosis treatment in Cape Town, South Africa: a qualitative analysis of programmatic change. Glob Health Action 5(1): 14385

Barnett J, Graham S, Mortreux C, Fincher R, Waters E, Hurlimann A (2014) A local coastal adaptation pathway. Nat Clim Chang 4:1103-1108. https://doi.org/10.1038/nclimate2383

Béland D, Howlett M (2016) The role and impact of the multiple-streams approach in comparative policy analysis. J Comp Policy Anal Res Pract 18:221-227. https://doi.org/10.1080/13876988.2016.1174410

Birk T (2012) Relocation of reef and atoll island communities as an adaptation to climate change: learning from experience in Solomon Islands. In: Hastrup K, Fog Olwig K (eds) Climate change and human mobility. Cambridge University Press, Cambridge, pp 81-109. https://doi.org/10.1017/CBO9781139235815.008

Bisaro A, de Bel M, Hinkel J, Kok S, Bouwer LM (2019) Leveraging public adaptation finance through urban land reclamation: cases from Germany, the Netherlands and the Maldives. Clim Chang. https://oi. org/10.1007/s10584-019-02507-5

Cairney P, Jones MD (2016) Kingdon's multiple streams approach: what is the empirical impact of this universal theory?: Kingdon's multiple streams approach. Policy Stud J 44:37-58. https://doi.org/10.1111/psj.12111

Campbell JL (1998) Institutional analysis and the role of ideas in political economy. Theory Soc 27:377-409

Cohen MD, March JG, Olsen JP (1972) A garbage can model of organizational choice. Admin Sci Q 17(1):1

Colton EOv (1995) The elite of the Maldives: sociopolitical organisation and change. London School of Economics and Political Science, United Kingdom

Dachary-Bernard J, Rey-Valette H, Rulleau et al (2019) Preferences among coastal and inland residents relating to managed retreat: influence of risk perception in acceptability of relocation strategies. J Environ Manag 232:772-780. https://doi.org/10.1016/j.jenvman.2018.11.104 
Dannenberg AL, Frumkin H, Hess JJ, Ebi KL (2019) Managed retreat as a strategy for climate change adaptation in small communities: public health implications. Clim Chang 153:1-14. https://doi.org/10.1007/s10584019-02382-0

Dovers SR, Hezri AA (2010) Institutions and policy processes: the means to the ends of adaptation: institutions and policy processes. Wiley Interdiscip Rev Clim Chang 1:212-231. https://doi.org/10.1002/wcc.29

Flick U (2014) The SAGE handbook of qualitative data analysis. SAGE Publications Ltd, 1 Oliver's Yard, 55 City Road, London EC1Y 1SP United Kingdom. https://doi.org/10.4135/9781446282243

Gayoom M (1987) Speech at UN general assembly, development and economic cooperation

Gibbs MT (2016) Why is coastal retreat so hard to implement? Understanding the political risk of coastal adaptation pathways. Ocean Coast Manag 130:107-114. https://doi.org/10.1016/j.ocecoaman.2016.06.002

Gussmann G, Hinkel J (2021) A framework for assessing the potential effectiveness of adaptation policies: Coastal risks and sea-level rise in the Maldives. Environ Sci Pol 115:35-42

Hanna C, White I, Glavovic B (2018) Managed retreat governance: insights from Matatā, New Zealand

Hanna C, White I, Glavovic B (2020) The uncertainty contagion: revealing the interrelated, cascading uncertainties of managed retreat. Sustainability 12:736. https://doi.org/10.3390/su12020736

Hauer ME, Fussell E, Mueller V, Burkett M, Call M, Abel K, McLeman R, Wrathall D (2019) Sea-level rise and human migration. Nat Rev Earth Environ. https://doi.org/10.1038/s43017-019-0002-9

Helmke G, Levitsky S (eds) (2006) Informal institutions and democracy: lessons from Latin America. Johns Hopkins Univ. Press, Baltimore

Herweg N, Huß C, ZohlnhöferR, (2015) Straightening the three streams: Theorising extensions of the multiple streams framework. EJPR 54(3):435-449. https://doi.org/10.1111/1475-6765.12089

Herweg N, Zahariadis N, Zohlnhöfer R (2018) The multiple streams framework: foundations, refinements, and empirical applications. In: Weible CM, Sabatier PA (eds) Theories of the policy process. Routledge, Fourth edition. Westview Press, Boulder, CO, 2017, pp 17-53. https://doi.org/10.4324/9780429494284-2

Hinkel J, Aerts JCJH, Brown S, Jiménez JA, Lincke D, Nicholls RJ, Scussolini P, Sanchez-Arcilla A, Vafeidis A, Addo KA (2018) The ability of societies to adapt to twenty-first-century sea-level rise. Nat Clim Chang 8: 570-578. https://doi.org/10.1038/s41558-018-0176-z

Hino M, Field CB, Mach KJ (2017) Managed retreat as a response to natural hazard risk. Nat. Clim Chang 7 : 364-370

Hirsch E (2015) “It won’t be any good to have democracy if we don't have a country": climate change and the politics of synecdoche in the Maldives. Glob Environ Chang 35:190-198. https://doi.org/10.1016/j. gloenvcha.2015.09.008

Hockly TW (1935) The two thousand isles: a short account of the people, history and customs of the Maldive archipelago. H.F. \& G. Witherby, London

Ibrahim IH (2016) Population relocation 1968-1997. URL http://www.ilyashussainibrahim.com/?p=286 (accessed 7.18.19)

IPCC, Houghton JT (1990) IPCC first assessment report. Intergovernmental Panel on Climate Change., \& World Meteorological Organization, Geneva, Switzerland

Jamero ML, Onuki M, Esteban M, Billones-Sensano XK, Tan N, Nellas A, Takagi H, Thao ND, Valenzuela VP (2017) Small-island communities in the Philippines prefer local measures to relocation in response to sealevel rise. Nat Clim Chang 7:581-586. https://doi.org/10.1038/nclimate3344

Kingdon JW (1984) Agendas, alternatives, and public policies. Boston : Little, Brown, [1984] @1984

Kothari U (2014) Political discourses of climate change and migration: resettlement policies in the Maldives: political discourses of climate change and migration. Geogr J 180:130-140. https://doi.org/10.1111 /geoj.12032

Lieberman ES (2001) Causal inference in historical institutional analysis: a specification of periodization strategies. Comp Polit Stud 34:1011-1035. https://doi.org/10.1177/0010414001034009003

Lincke D, Wolff C, Hinkel J, Vafeidis A, Blickensdörfer L, Skugor DP (2020) The effectiveness of setback zones for adapting to sea-level rise in Croatia. Reg Environ Chang 20(2)

Luetz J (2017) Climate change and migration in the Maldives: some lessons for policy makers. In: Leal Filho W (ed) Climate change adaptation in Pacific countries. Springer International Publishing, Cham, pp 35-69. https://doi.org/10.1007/978-3-319-50094-2_3

Mahoney J (2000) Path dependency in historical sociology. Theory Soc 29:507-548. https://doi.org/10.1023 /A:1007113830879

Malé Declaration (1989) Malé Declaration on global warming and sea level rise

Maniku HA (1990) Changes in the topography of the Maldives, forum of writers on environment (Maldives). Malé

Ministry of Environment and Energy (2011) State of the Environment 2011. http://www.environment.gov.mv/v2 /en/download/4270 
Ministry of Finance and Treasury (2012) Household income \& expenditure survey, 2009-2010. Statistics Division, Department of National Planning, Ministry of Finance and Treasury, Republic of Maldives, Male

Ministry of Home Affairs (2010) Decentralization act. Act on decentralization of the administrative divisions of the Maldives.

Mortreux C, Safra de Campos R, Adger WN, Ghosh T, Das S, Adams H, Hazra S (2018) Political economy of planned relocation: a model of action and inaction in government responses. Glob Environ Chang 50:123132. https://doi.org/10.1016/j.gloenvcha.2018.03.008

Munck af Rosenschöld J, Rozema JG, Frye-Levine LA (2014) Institutional inertia and climate change: a review of the new institutionalist literature: institutional inertia and climate change. Wiley Interdiscip Rev Clim Chang 5:639-648. https://doi.org/10.1002/wcc.292

Nafees AS (2005) An exploration of resettlement and its impact on social services: the case of the Maldives. Sch. Dev. Stud. Univ. East Angl. Master Thesis

NBS (2017) Statistical yearbook of Maldives 2016. National Bureau of Statistics, Ministry of Finance and Treasury

NBS (2018) Maldives population PROJECTIONS 2014-2054. National Bureau of Statistics, Republic of Maldives

NBS (2019) Maldives population projections 2014-2054, assumption and results analysis. National Bureau of Statistics Ministry of Finance and Treasury, Republic of Maldives

Oppenheimer M, Glavovic BC, Hinkel J, van de Wal R, Magnan AK, Abd-Elgawad A, Cai R, CifuentesJara M, DeConto RM, Ghosh T, Hay J, Isla F, Marzeion B, Meyssignac B, Sebesvari Z (2019) Sea Level Rise and Implications for Low-Lying Islands, Coasts and Communities. In: Pörtner H-O, Roberts DC, MassonDelmotte V, Zhai P, Tignor M, Poloczanska E, Mintenbeck K, Alegría A, Nicolai M, Okem A, Petzold J, Rama B, Weyer NM (eds) IPCC Special Report on the Ocean and Cryosphere in a Changing Climate In press

Orach K, Schlüter M, Österblom H (2017) Tracing a pathway to success: how competing interest groups influenced the 2013 EU common fisheries policy reform. Environ Sci Pol 76:90-102. https://doi. org/10.1016/j.envsci.2017.06.010

Ramm TD, Watson CS, White CJ (2018) Strategic adaptation pathway planning to manage sea-level rise and changing coastal flood risk. Environ Sci Pol 87:92-101. https://doi.org/10.1016/j.envsci.2018.06.001

Riyaz M, Park K-H (2010) "Safer island concept" developed after the 2004 INDIAN ocean tsunami: a CASE study of Maldives. J Earthq Tsunami 04:135-143. https://doi.org/10.1142/S1793431110000704

Robinson JJ (2016) The Maldives: what went wrong with the democracy experiment? Round Table 105:223225. https://doi.org/10.1080/00358533.2016.1154667

Sabatier PA (1987) Knowledge, policy-oriented learning, and policy change: an advocacy coalition framework. Knowledge 8:649-692. https://doi.org/10.1177/0164025987008004005

Shaig A (2008) Settlement planning for natural hazard resilience in small island states: the population and development consolidation approach

Siders AR (2019) Social justice implications of US managed retreat buyout programs. Clim Chang 152:239-257. https://doi.org/10.1007/s10584-018-2272-5

Siders AR, Hino M, Mach KJ (2019) The case for strategic and managed climate retreat. Science 365:761-763. https://doi.org/10.1126/science.aax 8346

Sovacool BK (2012) Perceptions of climate change risks and resilient island planning in the Maldives. Mitig Adapt Strateg Glob Chang 17:731-752. https://doi.org/10.1007/s11027-011-9341-7

Speelman LH, Nicholls RJ, Dyke J (2016) Contemporary migration intentions in the Maldives: the role of environmental and other factors. Sustain Sci:1-19. https://doi.org/10.1007/s11625-016-0410-4

Spohr F (2016) Explaining path dependency and deviation by combining multiple streams framework and historical institutionalism: a comparative analysis of German and Swedish labor market policies. J Comp Policy Anal Res Pract 18:257-272. https://doi.org/10.1080/13876988.2015.1122210

Stojanov R, Duží B, Kelman I, Němec D, Procházka D (2017) Local perceptions of climate change impacts and migration patterns in Malé, Maldives. Geogr J 183:370-385. https://doi.org/10.1111/geoj.12177

Storlazzi CD, Gingerich SB, van Dongeren A, Cheriton OM, Swarzenski PW, Quataert E, Voss CI, Field DW, Annamalai H, Piniak GA, McCall R (2018) Most atolls will be uninhabitable by the mid-21st century because of sea-level rise exacerbating wave-driven flooding. Sci Adv 4:eaap9741. https://doi.org/10.1126/sciadv.aap9741

Thelen K, Steinmo S (1992) Historical institutionalism in comparative politics. In: Steinmo S, Thelen K, Longstreth F (eds) Structuring politics. Cambridge University Press, Cambridge, pp 1-32. https://doi. org/10.1017/CBO9780511528125.002

Wadey M, Brown S, Nicholls RJ, Haigh I (2017) Coastal flooding in the Maldives: an assessment of historic events and their implications. Nat Hazards 89:131-159. https://doi.org/10.1007/s11069-017-2957-5

World Bank (2019) World development indicators, The World Bank. Country Profile Maldives

Zahariadis N (2014) Ambiguity and multiple streams., in: Theories of the Policy Process, Paul Sabatier, and Christopher Weible. Westview Press. Boulder 
Zahariadis N (2015) The shield of Heracles: multiple streams and the emotional endowment effect: the shield of Heracles. Eur J Polit Res 54:466-481. https://doi.org/10.1111/1475-6765.12072

Publisher's note Springer Nature remains neutral with regard to jurisdictional claims in published maps and institutional affiliations. 